Linköping Studies in Science and Technology Licentiate thesis No. 1829

\title{
Crack growth in single crystal nickel base superalloys under isothermal and thermomechanical fatigue
}

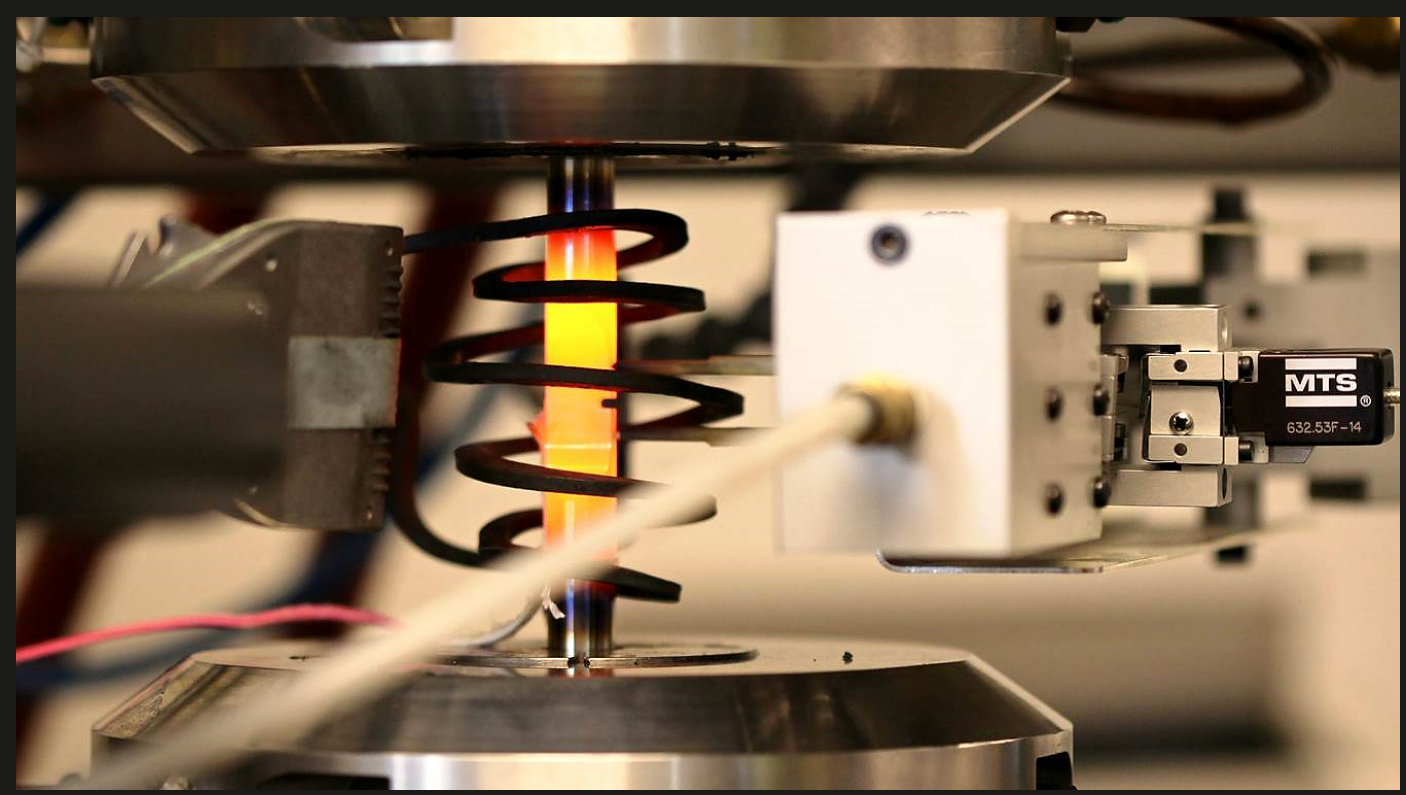

Frans Palmert

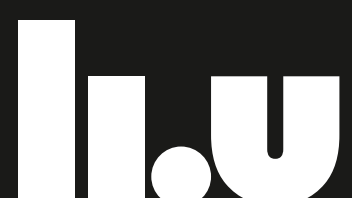


Linköping Studies in Science and Technology

Licentiate of engineering thesis No. 1829

\title{
Crack growth in single crystal nickel base superalloys under isothermal and thermomechanical fatigue
}

\author{
Frans Palmert
}

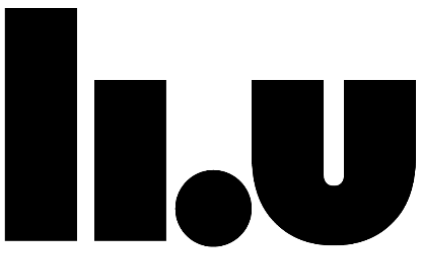

LINKÖPING UNIVERSITY

\author{
Division of Engineering Materials \\ Department of Management and Engineering \\ Linköping University, SE-581 83, Linköping, Sweden \\ http://www.liu.se
}

Linköping, January 2019 
Opponent: Professor Christer Persson, Chalmers University of Technology, Sweden. Date: January 25, 2019

Room: ACAS, Hus A, Campus Valla, Linköping University

Cover: Photo of TMF crack growth test setup, by Claes Isaksson

Printed by:

LiU-Tryck, Linköping, Sweden, 2018

ISBN: 978-91-7685-150-0

ISSN: 0280-7971

Distributed by:

Division of Engineering Materials

Department of Management and Engineering

Linköping University

SE-581 83, Linköping, Sweden

\section{(C) 2018 Frans Palmert}

No part of this publication can be reproduced, stored in a retrieval system, or transmitted, in any form or by any means 


\section{Preface}

This licentiate of engineering thesis is the product of a close collaboration between Linköping University and Siemens Industrial Turbomachinery $A B$ in Finspång, Sweden. I gratefully acknowledge the financial support which has been received from the Swedish Energy Agency and Siemens Industrial Turbomachinery AB, via the Research Consortium of Materials Technology for Thermal Energy Processes, Grant No. KME-702.

I find it very inspiring to work as an industrial $\mathrm{PhD}$ student at Linköping University, which is an environment of cutting edge research in many different fields. Simultaneously working at Siemens ensures a thorough insight into the industrial applications of the research, which for me has provided an additional motivation beyond the purely scientific thirst for knowledge. In both work places I have had the privilege of collaborating with colleagues who possess expert knowledge in their respective fields and also an eagerness to share this knowledge. I would like to thank Helena Oskarsson and David Gustafsson at Siemens Industrial Turbomachinery and Johan Moverare at Linköping University for making my industrial $\mathrm{PhD}$ studies possible. Johan and David, together with Mikael Segersäll, also provided much appreciated support, guidance and expert input as my supervisors. I am also very grateful for all the valuable discussions and input provided by the rest of my project group: Christian Busse, Daniel Leidermark, Kjell Simonsson, Per Almroth, Magnus Hasselqvist and Björn Sjödin. I would like to thank my TMF testing colleague Claes Isaksson at Siemens, for keeping a positive can-do attitude through all the nitty gritty problem solving, brainstorming and debugging. I also thank my current manager Hanna Sivervik at Siemens for supporting my PhD studies.

Finally I would like to thank my family and friends, for enriching my life in many different ways. Tack älskade Ida för att du vill dela ditt liv med mig och för att du påminner mig om vad som är viktigt! Tack Albin för allt roligt vi hittar på och alla funderingar du delar med dig av! Tack Emil för att du är en sådan glädjespridare!

Frans Palmert

Finspång, December 2018 


\section{Abstract}

This work concerns the fatigue crack growth behaviour of nickel base single crystal superalloys. The main industrial application of this class of materials is in gas turbine blades, where the ability to withstand severe mechanical loading in combination with high temperatures is required. In order to ensure the structural integrity of gas turbine blades, knowledge of the fatigue crack growth behaviour under service-like conditions is of utmost importance. The aim of the present work is both to improve the understanding of the crack growth behaviour of single crystal superalloys and also to improve the testing and evaluation methodology for crack propagation under thermomechanical fatigue loading conditions. Single crystal superalloys have anisotropic mechanical properties and are prone to localization of inelastic deformation along the close-packed planes of the crystal lattice. Under some conditions, crystallographic crack growth occurs along these planes and this is a complicating factor throughout the whole chain of crack propagation life simulation; from material data generation to component calculation. Fatigue crack growth testing has been performed, both using conventional isothermal testing methods and also using thermomechanical fatigue crack growth testing. Experimental observations regarding crystallographic crack growth have been made and its dependence on crystal orientation and testing temperature has been investigated. Quantitative crack growth data are however only presented for the case of Mode I crack growth under isothermal as well as thermomechanical fatigue conditions. Microstructural investigations have been undertaken to investigate the deformation mechanisms governing the crack growth behaviour. A compliance based method for the evaluation of crack opening force under thermomechanical fatigue conditions was developed, in order to enable a detailed analysis of the test data. The crack opening force evaluation proved to be of key importance in the understanding of the crack driving force under different testing conditions. 


\section{List of papers}

In this licentiate of engineering thesis, the following papers are included:

\section{Paper 1}

Palmert, F., Moverare, J., Gustafsson, D., and Busse, C. (2018). "Fatigue crack growth behaviour of an alternative single crystal nickel base superalloy", International Journal of Fatigue 109

\section{Paper 2}

Palmert, F., Moverare, J., Gustafsson, D., "Thermomechanical fatigue crack growth in a single crystal nickel base superalloy", Submitted for publication

\section{Own contribution}

The mechanical testing covered in Paper 1 has been performed by Prof. Johan Moverare at Linköping University. The mechanical testing covered in Paper 2 has been performed by me. All test data evaluation and microscopy, for both papers, has been performed by me. The major part of the writing of the abovementioned papers has been done by me. For the work presented in this licentiate of engineering thesis I am to hold the primary responsibility. 


\section{Contents}

Preface.........................................................ii

Abstract........................................................v

List of papers.............................................vii

Part 1 Background \& Methodology....................1

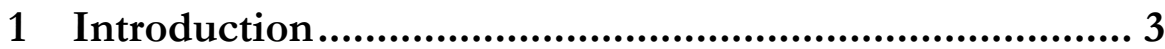

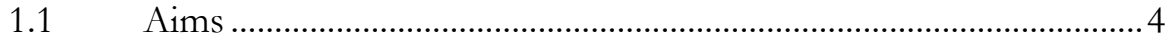

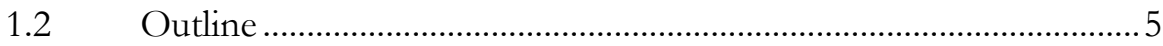

2 Gas turbines............................................................... 7

3 Nickel base superalloys .................................................... 9

3.1 Single crystal nickel base superalloys.............................................11

$4 \quad$ Fatigue crack propagation................................................15

4.1 Fatigue crack propagation of single crystal superalloys ..................18

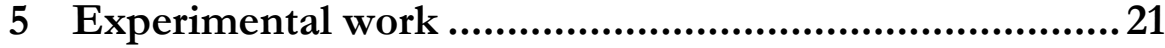

5.1 Isothermal crack growth testing of DCT specimens .....................21

5.2 TMF and isothermal crack growth testing of SEN specimens......22

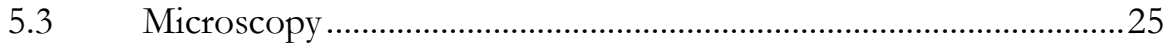

6 Summary of findings...........................................................27

7 Conclusions ………………………................................... 31

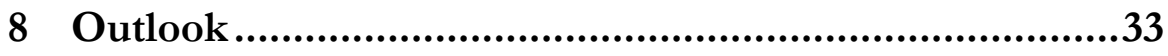

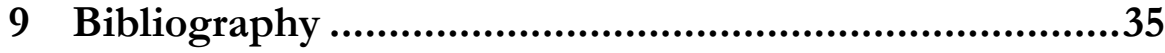

Part 2 Appended papers............................45

Paper 1:

Fatigue crack growth behaviour of an alternative single crystal nickel base superalloy

Paper 2:

Thermomechanical fatigue crack growth in a single crystal nickel base superalloy 


\section{Part 1 \\ Background \& Metodology}




\section{Introduction}

Global warming as a result of greenhouse gas emissions is widely recognized as a serious threat to the environment ${ }^{1}$. Gas turbines can play an important role in the reduction of greenhouse gas emissions associated with electricity production. Renewable energy sources such as wind power and solar power are by nature intermittent and the possibilities of efficient energy storage are currently limited. When the intermittent energy sources are unavailable, a gas turbine may be used as a complementary source of electricity. Such complementary power capacity is vital in an energy system relying heavily on intermittent energy sources. Gas turbines supplying such complementary power will experience frequent starts and stops, which implies frequent thermomechanical fatigue cycling of critical components such as turbine blades. Traditionally, land-based gas turbines have been designed for base-load operation with a lower start/stop frequency and hence lower demands on cyclic life. The frequent cycling operating profile puts new demands on the cyclic life of gas turbine components. Whilst meeting the demands for cyclic operation there is also a constant ambition to maximize the efficiency of the gas turbine. Increased efficiency can be obtained either by increasing the turbine inlet temperature, or by decreasing the cooling air consumption of cooled components. Both these measures to increase efficiency tend also to increase the component metal temperatures and thus increase the severity of thermomechanical fatigue (TMF) loadings on the critical turbine components. Therefore, there is a high demand for improved fatigue life prediction methodology. Improving the accuracy and reliability of fatigue life predictions enables a reduction of safety factors and thus an increase of the useful predicted cyclic life. For gas turbine blades, the crack propagation life is in many cases substantially longer than the crack initiation life and should therefore be adequately accounted for in lifing calculations. Understanding of the crack propagation behaviour is also of vital importance for the assessment of the severity of potential casting defects. The present work aims to provide improved knowledge of the fatigue crack growth behaviour in single crystal nickel base superalloys, which is a class of materials frequently used for first stage gas turbine blades. These alloys are anisotropic, both in terms of elastic and inelastic mechanical properties ${ }^{2}$. Inelastic deformation is typically localized to the close-packed $\{111\}$ planes at low to moderate temperatures, whereas both octahedral slip and cube slip processes are active at higher temperatures (above approximately $600^{\circ} \mathrm{C}$ for strain rates $\left.>10^{\wedge-4} \mathrm{~s}^{-1}\right)^{3}$. Under some conditions, crystallographic crack growth along $\{111\}$ planes is observed. The complex material behaviour of single 
crystals makes it more difficult to model the crack growth, both in the context of component simulations but also in the context of test data evaluation. For crystallographic cracks, growing non-perpendicularly to the loading direction it is not self-evident how to define the crack driving force. Several researchers propose crack driving force parameters based on shear stress intensity factors resolved onto the $\{111\}$ planes ${ }^{4,5,6,7,8,9}$, but there is no general consensus regarding the precise definition. Within the present licentiate of engineering thesis work, testing was done to investigate the crystallographic crack growth behaviour under different testing conditions and the results were used in the development of the crystallographic crack driving force parameter recently proposed by Busse et al. ${ }^{9,10}$. While the complexity of localized inelastic deformation and crystallographic crack growth is mainly associated with lower temperatures, there are other challenges associated with fatigue crack growth in single crystal superalloys at higher temperatures. At higher temperatures, the crack growth may be influenced by creep, oxidation and microstructural degradation. TMF crack growth testing, resembling service conditions, is generally required to accurately characterize the material behaviour ${ }^{11,12,13,14}$. TMF of nickel base superalloys has been studied previously, but the majority of the work has been concerning the cyclic deformation behaviour and crack initiation life $\mathrm{e}^{15,16,17,18,19,20,21,22,23,24,25,26,27,28}$. Only limited work has been done to study the crack growth behaviour under TMF conditions ${ }^{29,30,31,32,33,34}$. In the present work, TMF crack growth testing is performed and a method is developed to experimentally evaluate the crack opening stress under TMF conditions. It was shown that crack closure had a major influence on the crack growth rates.

\subsection{Aims}

The present work has two major aims, one which is related to the investigation of material behaviour and one which is related to the development of material testing methodology.

\section{Aim 1:}

To improve the understanding of the fatigue crack growth behaviour of single crystal nickel base superalloys, under conditions representative of gas turbine blades.

\section{Aim 2:}

To improve the testing and evaluation methodology for TMF crack growth.

Aim 1 serves to enable improvements in the accuracy of crack growth modelling for single crystal gas turbine blades specifically. The work done towards "Aim 2" is generally applicable to a wide range of materials and structural components. 


\subsection{Outline}

This licentiate of engineering thesis consists of two parts. Part 1 gives an introduction to single crystal nickel base superalloys and their application as gas turbine blade materials. Previous research regarding the fatigue crack growth behaviour of single crystal nickel base superalloys is also presented. The experimental work is briefly described and the major findings of the work are summarized. Part 2 of the thesis contains two appended papers. 


\section{Gas turbines}

In a gas turbine engine, mechanical work is extracted from a continuous stream of hot gas. The hot gas stream is generated by combustion of fuel, mixed with the compressed air. The three main parts of the gas turbine engine are the compressor, combustion chamber and turbine. Figure 1 shows the industrial gas turbine SGT-800 as an example of a typical design for electrical power generation. Air enters through the inlet and passes through the compressor, where its pressure and temperature is increased. The compressed air then enters the combustion chamber, where fuel is injected and continuously combusted to create a stream of hot gas. The hot gas flows through the turbine section, thus causing the turbine blades to rotate. In case of the SGT-800, the turbine section consists of three rows of turbine blades. The temperature and pressure of the gas stream is highest at the first row of blades and then gradually decreases in later stages as energy is extracted from the gas stream. In order to withstand the high operating temperature of the first turbine stage, single crystal nickel base superalloys are often used. The first stage blades are cooled by air from the compressor and usually coated a by a thermal barrier coating (TBC) in order to reduce the metal temperature. The metal temperature of a gas turbine blade during operation varies strongly from the root of the blade, attached to the turbine disc, to the tip of the blade. For a stage 1 blade, the metal temperature is typically around $500^{\circ} \mathrm{C}$ in the root and approximately $1000^{\circ} \mathrm{C}$ at the tip. The blades are connected to a shaft which transfers the mechanical work extracted in the turbine section. Part of this work is needed to drive the compressor. The remaining useful work is converted into electrical energy in a generator connected to the shaft. 


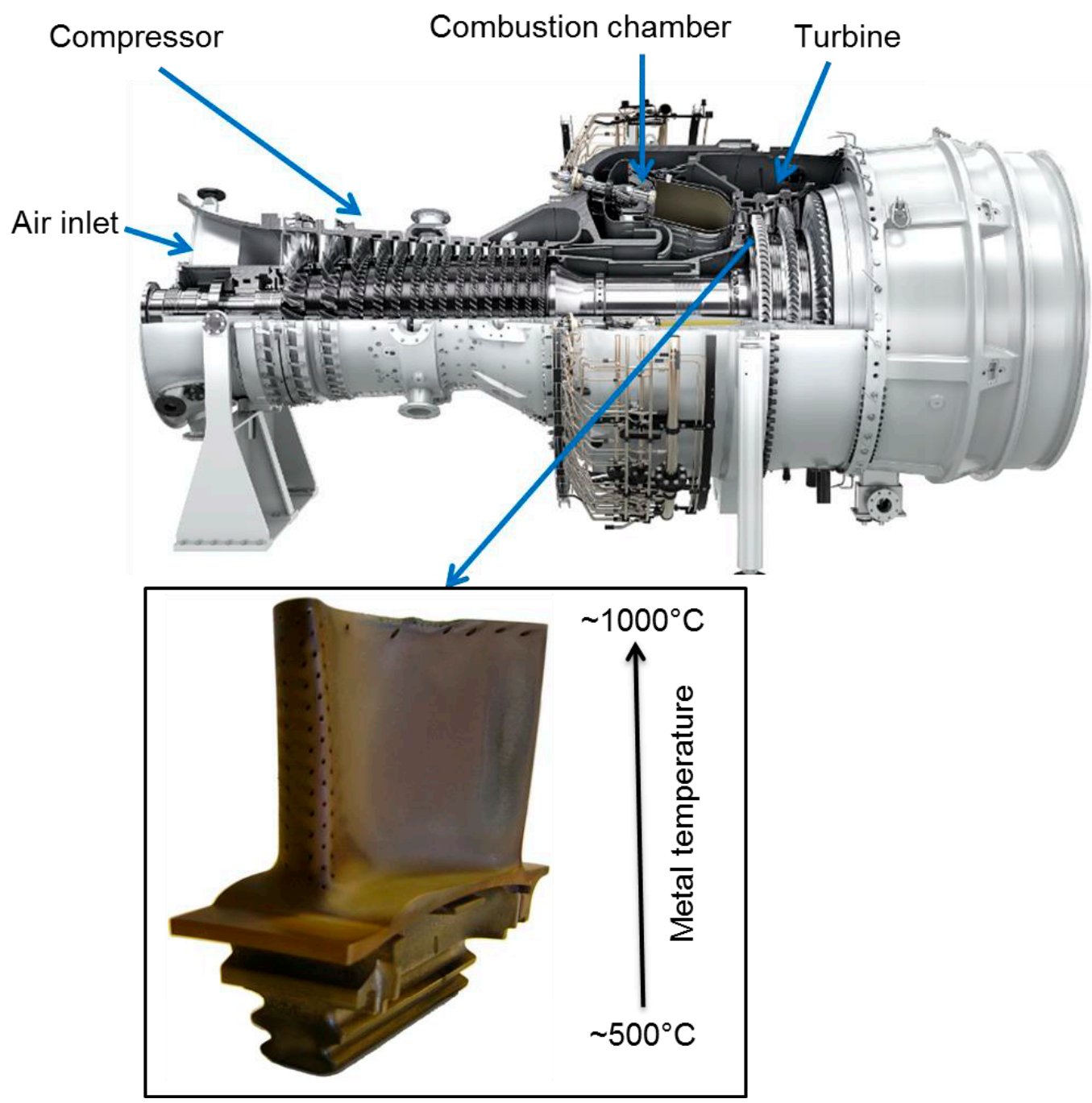

Figure 1 - Industrial gas turbine SGT-800 and service exposed first stage turbine blade with indication of the variation in metal temperature along the radial direction. Courtesy of Siemens Industrial Turbomachinery AB. 


\section{Nickel base superalloys}

In nickel base alloys, excellent high temperature strength and creep resistance can be achieved. These high temperature materials, together with other alloys based on cobalt or nickel-iron, are commonly referred to as superalloys. Nickel base superalloys typically contain more than 10 different alloying elements. The matrix of the nickel base alloys is a disordered face centered cubic (FCC) phase. An important reason for the choice of nickel as the base for these high temperature materials is the stability of FCC-Ni at all temperatures up to the melting point ${ }^{35}$. Volume changes associated with phase transformations would cause problems in high temperature service. Nickel base alloys are tough and ductile, with no brittle to ductile transition temperature as observed in materials with body centered cubic (BCC) crystal structure. Furthermore, the diffusion rate is low in the FCC structure, resulting in microstructural stability and low rates of thermally activated creep at elevated temperatures ${ }^{35}$. Among the nickel base alloys, a wide variation of mechanical properties is found depending on the dominating hardening mechanism. The alloys are classified as either solution strengthened or precipitation strengthened. The solution strengthened alloys contain elements such as W, Re, Mo, with large atomic radii. The introduction of these atoms results in distortions of the crystal lattice, which restrict dislocation movements and thereby prevent plastic deformation. Although the alloys are not referred to as precipitation strengthened, they do contain various amounts of carbide precipitates. The carbides are formed at grain boundaries and significantly improve the resistance to creep deformation, by restricting grain boundary sliding ${ }^{36}$. These alloys can be wrought and are used for gas turbine components where the mechanical loading is relatively low. The focus of the present work is on alloys for turbine blades and vanes, which are precipitation strengthened with $\gamma^{\prime}$ particles. The $\gamma^{\prime}$ phase consists of $\mathrm{Ni}_{3}(\mathrm{Al}, \mathrm{Ti}, \mathrm{Ta})$ in an ordered FCC crystal structure, where $\mathrm{Al}$, $\mathrm{Ti}$ and $\mathrm{Ta}$ atoms occupy the unit cell corners and $\mathrm{Ni}$ atoms occupy the centers of the unit cell faces. The unit cell of pure $\mathrm{Ni}_{3} \mathrm{Al}$ is shown in Figure $2 \mathrm{a}$. A backscattered electron micrograph of a typical $\gamma / \gamma^{\prime}$ microstructure is shown in Figure $2 b$, where the bright phase is $\gamma^{\prime}$ and the darker matrix phase is $\gamma$. 

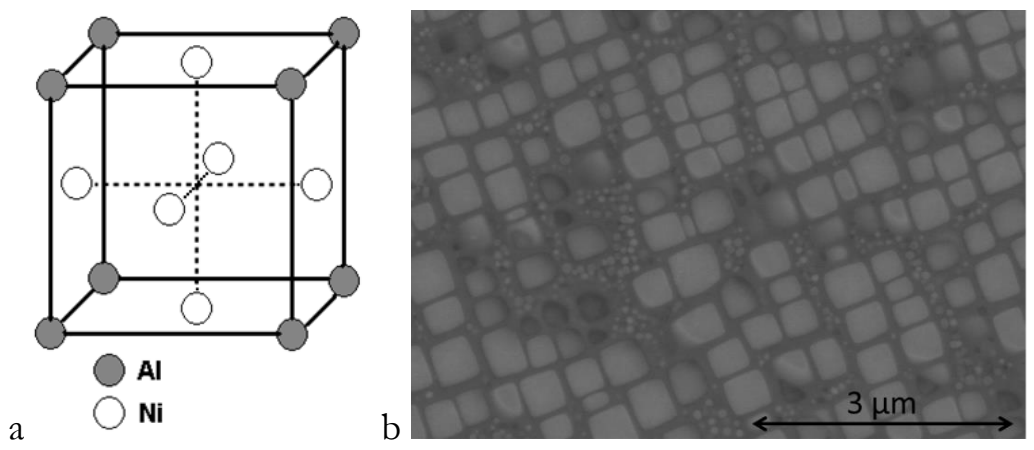

Figure 2-a: Unit cell of the $\mathrm{Y}^{\prime} \mathrm{Ni}_{3} \mathrm{Al}$ phase. b: Backscattered electron micrograph of a typical $Y / Y^{\prime}$ microstructure. The bright phase is $Y^{\prime}$ and the darker phase is $Y$.

The ordered crystal structure is formed because $\mathrm{Ni}-\mathrm{Al}$ bonds are more energetically favourable than $\mathrm{Ni}-\mathrm{Ni}$ or $\mathrm{Al}-\mathrm{Al}$ bonds ${ }^{37}$. Since $\gamma^{\prime}$ has the same crystal structure as the matrix phase $\gamma$, the particles are coherent and the interfacial energy is relatively low. In efforts to improve the creep resistance the content of $\gamma^{\prime}$ has been increased over the years. The $\gamma^{\prime}$ fraction is controlled by adjusting the amount of $\gamma^{\prime}$ formers, such as $\mathrm{Al}$, $\mathrm{Ti}, \mathrm{Ta}$, and $\gamma$ stabilizers, such as $\mathrm{Cr}^{38}$. The morphology of the particles is strongly influenced by the misfit of lattice parameters between $\gamma$ and $\gamma^{\prime}$, see Eq. (1).

$\delta=2 * \frac{a_{\gamma^{\prime}}-a_{\gamma}}{a_{\gamma^{\prime}}+a_{\gamma}}$

In Eq. (1), $\delta$ is the lattice misfit and $a_{\gamma}$ and $a_{\gamma^{\prime}}$ denote the lattice parameters of the respective phases. The lattice parameters of $\gamma$ and $\gamma^{\prime}$ are similar and both negative and positive misfit values are possible. The $\gamma^{\prime}$ particles tend to be cuboidal at small absolute misfit values and spheroidal at higher values ${ }^{39}$. This reflects the increase of interfacial energy with increasing lattice misfit. The tendency towards minimization of specific area of the particles increases with increasing interfacial energy. The lattice misfit depends on the chemical composition of the phases and on the temperature.

The ordered structure of the $\gamma^{\prime}$ phase is responsible for a substantial hardening effect. A dislocation moving through the $\gamma$ matrix phase cannot pass through a $\gamma^{\prime}$ particle, without introducing a displacement of the $\gamma^{\prime}$ lattice, forcing the formation of an antiphase boundary which implies the formation of high energy $\mathrm{Ni}-\mathrm{Ni}$ and $\mathrm{Al}-\mathrm{Al}$ bonds. The crystallographic order can be restored by a second dislocation passing through the same particle. In order for dislocations to be able to cut through a $\gamma^{\prime}$ particle, they are therefore required to move through the particle in pairs of coupled dislocations. The dislocations are considered weakly coupled if the distance between 
them is large compared to the particle diameter and strongly coupled if the distance between the dislocations is comparable to the particle diameter. In the case of weak coupling, the particle strengthening effect increases with increasing particle diameter, whereas in the case of strong coupling it decreases with increasing particle diameter. It has been shown theoretically and experimentally that the particle size corresponding to the transition from weak to strong coupling yields the maximum strengthening effect ${ }^{40}$. However, this theoretical prediction is based on the assumption that the fraction of $\gamma^{\prime}$ particles is small, which is usually not the case for turbine blade alloys. The creep resistance of the $\gamma^{\prime}$ phase is higher than that of the $\gamma$ phase, but the creep resistance does not increase monotonically with $\gamma^{\prime}$ fraction. The optimum gamma prime content with respect to creep resistance depends on the chemical composition of the respective phases and also on the specific temperature and stress level for which the creep resistance is evaluated. Murakumo et al. conducted a study where single crystal nickel base superalloys were produced with the same chemical composition of the $\gamma$ and $\gamma^{\prime}$ phases but with different volume fractions of $\gamma^{\prime}$. They tested two different creep conditions and found an optimum $\gamma^{\prime}$ fraction of around $65 \%$ for both conditions ${ }^{41}$. It should be mentioned that both of the evaluated creep conditions correspond to creep rupture times below $1000 \mathrm{~h}$. This is a very short time compared to the service life of a gas turbine blade in a land-based gas turbine and hence the creep mechanisms and microstructural degradation processes relevant to land-based gas turbines may not have been captured in the creep evaluation. The creep evaluation, and thereby the optimization of the $\gamma^{\prime}$ fraction may on the other hand be much more relevant for gas turbine blades in aero engines, where the total accumulated time at creep critical temperatures is much shorter.

\subsection{Single crystal nickel base superalloys}

Gas turbine blade alloys strengthened with $\gamma^{\prime}$ particles are cast directly into their final shape, using investment casting. For the most demanding applications, such as first stage turbine blades, the components are often cast in single crystal form. By eliminating the grain boundaries, creep resistance is considerably improved since the creep of polycrystalline alloys is associated with grain boundary sliding and cavitation $^{36}$. An improvement can also be achieved in the oxidation resistance, since oxidation often takes place preferentially along grain boundaries. During casting the material is melted in a vacuum furnace and then retracted from the furnace, while the leading surface of the cast is being cooled. The thermal gradient formed in the cast causes columnar grains to grow parallel to the direction of retraction. The crystal structure formed has one of the crystal lattice vectors aligned parallel with the direction of retraction, i.e. the axial direction of the blade. Single crystal solidification can be achieved by using a grain selector or a seed crystal. The grain selector is 
typically a narrow spiral through which only one grain can grow. The grain selector thus selects one of the initially formed columnar grains to be the grain making up the cast component, see Figure 3.

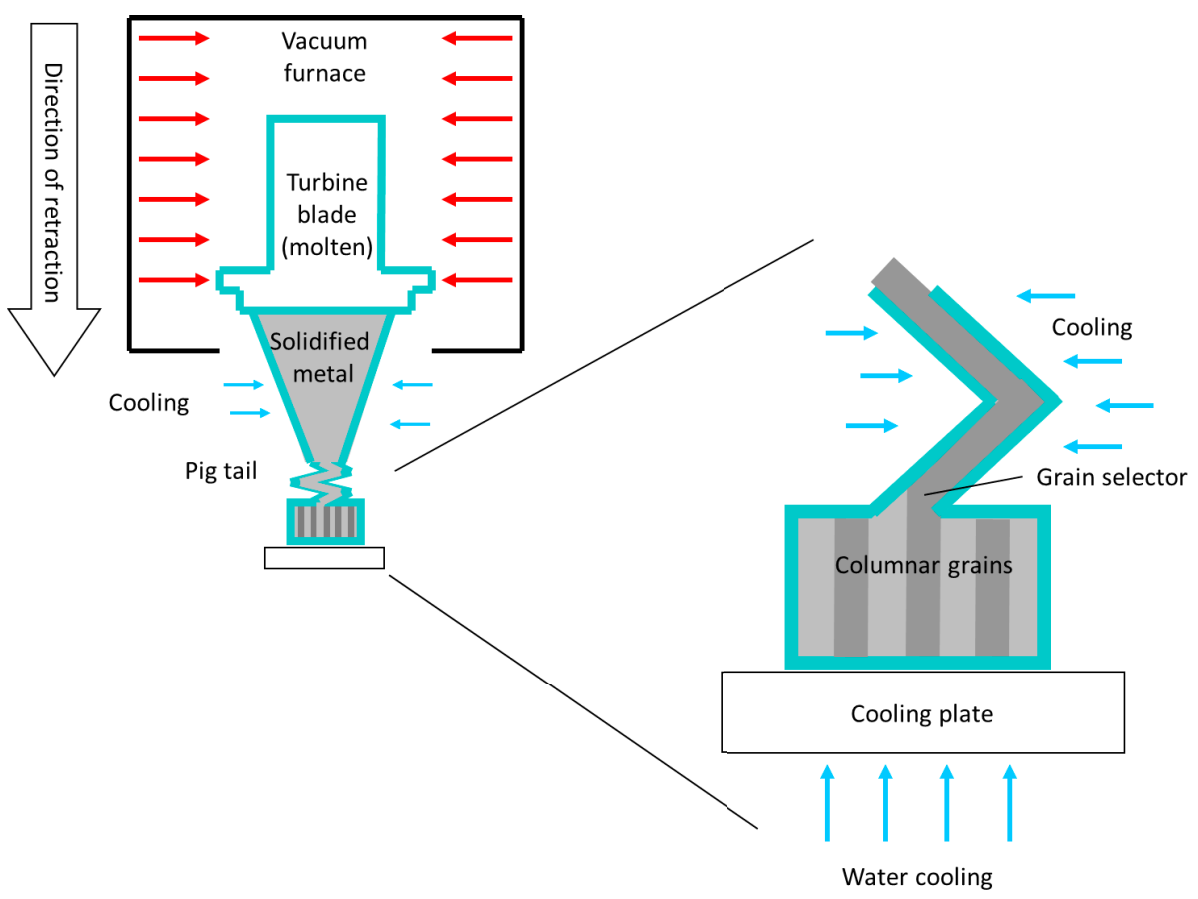

Figure 3 - Function of the grain selector in single-crystal casting of a turbine blade. Figure from PhD thesis by Segersäll, reproduced with permission of the author ${ }^{42}$.

The secondary orientation of the crystal structure is not controlled when a grain selector is used. The secondary crystal orientation may be controlled by the use of a seed crystal, at which the solidification starts. The crystal alignment of the entire cast component is then controlled by the alignment of the seed crystal. By a similar casting process, without grain selector or seed crystal, a directionally solidified columnar grained component may be produced. In this case the grains are aligned along the direction in which the component is to be loaded. No transverse grain boundaries are present, which would decrease the resistance to creep deformation. Both in the case of directionally solidified blades and single-crystal blades, a $<001>$ crystal direction is aligned parallel to the axial direction of the blade, i.e. the direction of the centrifugal force during service. It is an important advantage that the $<001\rangle$ directions are the natural dendritic growth directions for nickel base alloys, since the mechanical properties in these directions are well suited to the application. The $<001>$ directions 
have the lowest elastic modulus, which is less than half of the elastic modulus in the $<111>$ directions ${ }^{43}$. Since potential sites for fatigue crack initiation in a turbine blade are associated with stress concentrations, the loading is locally strain controlled. The low elastic modulus decreases the local plastic deformation and thereby the risk of fatigue damage.

The material studied in the present work is a single crystal nickel base superalloy, similar to the alloy described in a publication by Reed et $\mathrm{al}^{44}$. Its main alloying elements, in order of decreasing $\mathrm{wt} \%$, are as follows: Ni-Cr-Ta-Co-Al-W-Mo-Si-Hf-CCe. The microstructure mainly consists of a $\gamma$-matrix precipitation strengthened by approximately $50 \mathrm{vol} \%$ of $\gamma^{\prime}$ particles. The majority of the $\gamma^{\prime}$ is in the form of primary cuboidal particles, but smaller secondary $\gamma^{\prime}$ particles are also present within the $\gamma$ channels. In addition, the microstructure also contains carbides and casting pores. The alloy has been designed specifically for the operating conditions of a first stage industrial gas turbine blade, which implies a need for a combination of high oxidation and corrosion resistance as well as useful creep resistance at moderate temperatures and long times. The development of single crystal superalloys has traditionally been driven by the material requirements associated with use in aero engines and these alloys have been used also in industrial gas turbines although they are not optimized for the operating conditions of an industrial gas turbine ${ }^{44}$. An important difference in operating conditions between a land-based industrial gas turbine and an aero engine is that an aero engine only operates close to its maximum power output for a limited amount of time during take-off and landing, whereas an industrial gas turbine typically operates continuously at a relatively high power output. This difference must be taken into consideration when evaluating the creep performance of gas turbine blade alloys for application in aero engines or land-based gas turbines. Whereas short-term creep tests may provide a useful measure to compare the creep performance in an aero engine context, the same measure is typically not applicable as a performance indicator for land-based gas turbines, where long-term microstructural degradation often plays a more important role and long-term creep testing is required to capture the material behaviour. For the single crystal nickel base superalloy CMSX-4, Bullough et al. have demonstrated that non-conservative results may be obtained when extrapolating from creep data at high temperatures and short times to lower temperatures and longer times ${ }^{45}$. 


\section{Fatigue crack propagation}

For structures subjected to repeated cyclic loading, there is a risk of fatigue failure and the assessment of the number of cycles to fatigue failure is of major technical importance. For modelling purposes, the fatigue process is often divided into two stages: fatigue crack initiation and fatigue crack propagation. The total number of cycles to fatigue failure, $\mathrm{N}_{\text {tot }}$ is the sum of the number of cycles to crack initiation $\mathrm{N}_{i}$ and the number of cycles spent in crack propagation to failure, $N_{p}: N_{t o t}=N_{i}+N_{p}$. In order to conservatively estimate the fatigue life of a component, both $\mathrm{N}_{\mathrm{i}}$ and $\mathrm{N}_{\mathrm{p}}$ must be conservatively estimated. In some cases, this implies the assumption of $N_{p}=0$, due to lack of a calibrated crack growth model. For gas turbine blades, $N_{p}$ is often substantially greater than $N_{i}$ and highly conservative results are thus obtained if $N_{p}$ is neglected. In cases where initial material defects are present, it may be necessary to assume $N_{i}=0$ and the useful fatigue life assessment is then completely reliant on the prediction of $N_{p}$. In light of this, there is a strong motivation to predict $N_{p}$. Such a prediction relies on a suitable definition of crack driving force (CDF). In case of linear elastic material behaviour, the stress intensity factor $(K)$ is used to characterize the local stresses in the vicinity of the singularity associated with the crack tip ${ }^{46}$. A subscript is used to denote the mode of fracture: $K_{I}$ for opening, $K_{I I}$ for in-plane shear and $K_{I I I}$ for out-of-plane shear. $K_{I}$ is related to the far field stress $\left(\sigma_{\infty}\right)$ and crack length (a) according to Eq. (2).

$K_{I}=f(a) * \sigma_{\infty} \sqrt{\pi a}$

In Eq. (2), $\mathrm{f}(\mathrm{a})$ is a geometry function, which may be derived analytically for idealized geometries or determined by finite element simulations for complex geometries. In the present licentiate of engineering thesis and associated articles $K_{I}$ is referred to as $K$. For linear elastic material behaviour $K$ is directly related to the rate of change of potential energy with respect to crack area, also known as the energy release rate, $G^{46}$. The energy release rate approach was proposed by $\operatorname{Irwin}^{47}$, based on previous work by Griffith $^{48}$. The stress intensity factor range $\Delta K$ is often used as CDF, see Eq. (3). In cases where the crack is closed during part of the fatigue cycle it is relevant to consider the effective stress intensity factor range $\Delta K_{e f f}$ as proposed by Elber ${ }^{49}$, see Eq. (4). 
$\Delta K=K_{\max }-K_{\min }$

$\Delta K_{\text {eff }}=K_{\text {max }}-K_{\text {open }}$

In the above equations, $K_{\max }$ and $K_{\min }$ are the maximum and minimum stress intensity factors of the cycle and $K_{\text {open }}$ is the stress intensity factor at crack opening. Most materials display three distinct regions of fatigue crack growth, as shown in Figure 4. Below the threshold stress intensity factor range $\Delta K_{t h}$ no crack growth takes place. In region $\mathrm{I}$, just above $\Delta K_{t}$, the crack growth rate $(\mathrm{da} / \mathrm{dN})$ is low but rapidly increasing with increasing $\Delta K$. In region II, the crack growth is stable on the macroscopic scale and $\mathrm{da} / \mathrm{dN}$ is usually well described by Paris' law, see Eq. (5). This is an empirical relationship, originally observed by Paris et $\mathrm{al}^{50}$.

$\frac{\mathrm{d} a}{\mathrm{~d} N}=C \cdot \Delta K^{m}$

In Eq. (5), $C$ and $\mathrm{m}$ are fitting parameters. Paris' law can be used in a generalized form where $\Delta K$ is replaced by any other crack driving force parameter, e.g. $\Delta K_{e f f}$ If da/dN is correlated against $\Delta K$, it is to be expected that da/dN depends also on the stress ratio R. R is defined in Eq. (6), where $\sigma_{\min }$ and $\sigma_{\max }$ denote the minimum and maximum nominal stress of the fatigue cycle.

$R=\frac{\sigma_{\min }}{\sigma_{\max }}$

In region III, $K_{\max }$ approaches the fracture toughness $\left(K_{I C}\right)$ of the material and da/dN increases rapidly due to unstable crack growth. 


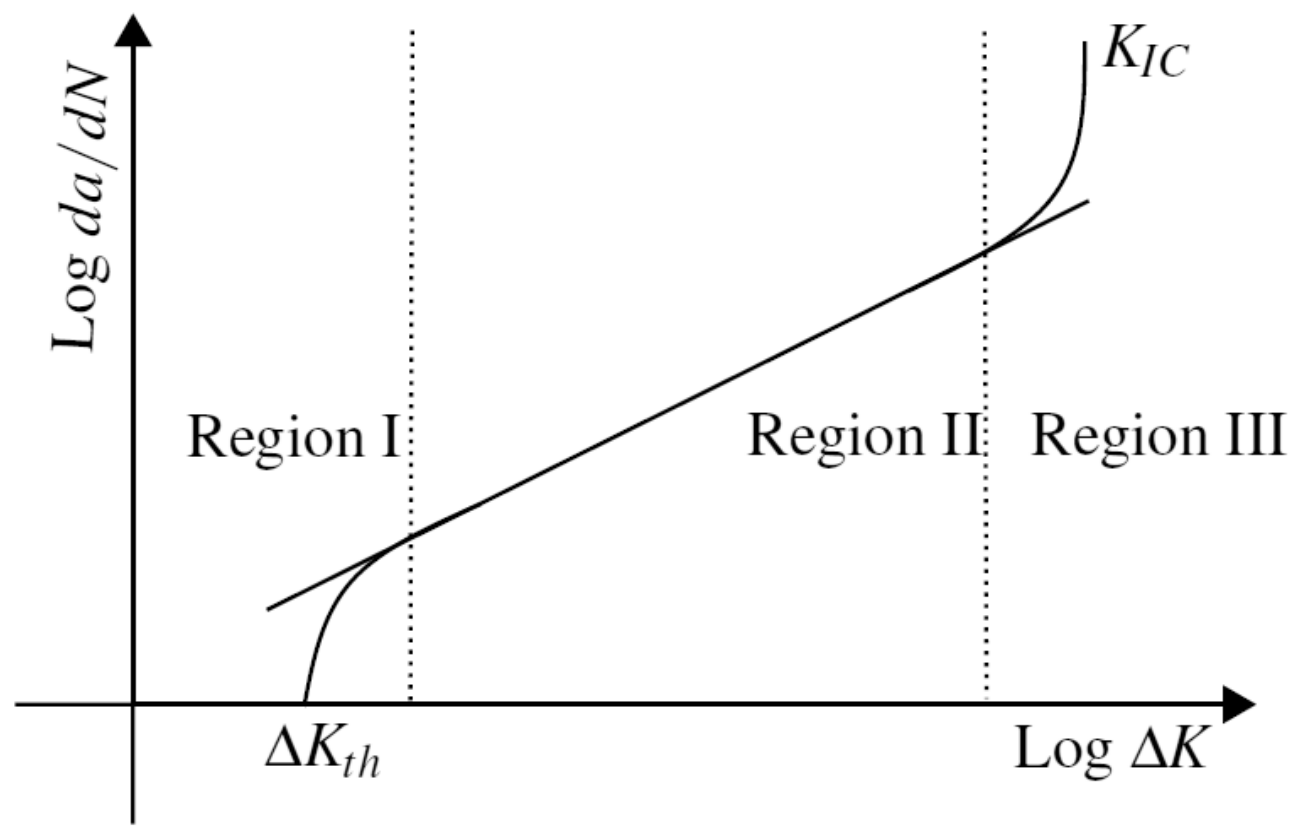

Figure 4 - Fatigue crack propagation regions. Diagram from licentiate of engineering thesis by Busse, reproduced with permission of the author ${ }^{51}$.

The concept of stress intensity factor is based on the assumption of linearly elastic behavior, with infinite stresses at the crack tip. In reality, the crack tip stress is relaxed by inelastic deformation of the material close to the crack tip. If the zone of inelastic deformation around the crack tip is small, the inaccuracy associated with the assumption of linear elasticity is also small. If the size of the zone of inelastic deformation is moderate, $K$ may still provide a useful measure of the crack driving force if a correction is applied to $K^{46,52,53,54}$. In the case of more extensive inelastic deformation it may be necessary to use a nonlinear fracture mechanics parameter such as crack tip opening displacement (CTOD) or the J contour integral. The J integral was originally presented by Rice ${ }^{55}$ and it provides a description of the energy release rate which does not rely on the assumption of linear elastic material behaviour. It does however rely on the assumption that the inelastic deformation can be idealized as nonlinear elastic ${ }^{46}$. For a material undergoing steady-state creep, the crack growth may be characterized by the $\mathrm{C}^{*}$ integral, which is defined based on the $\mathrm{J}$ integral by replacing strains with strain rates and displacements with displacement rates ${ }^{46,56,57}$.

For the test data evaluation of the present work, only linear elastic fracture mechanics has been used. In the analysis of the obtained crack growth data it was found that $\Delta K$ or $\Delta K_{e f f}$ provided useful measures of the crack driving force. 


\subsection{Fatigue crack propagation of single crystal superalloys}

For gas turbine blades, there are two principal types of fatigue: low-cycle, thermomechanical fatigue, associated with starting and stopping the turbine and high-cycle fatigue, arising from resonant vibrations of the blades. The high cycle fatigue usually occurs under more or less isothermal conditions and isothermal fatigue testing is therefore relevant. The low cycle fatigue associated with starting and stopping the turbine occurs under nonisothermal conditions and TMF testing is generally required to obtain relevant data. If the maximum temperature of the TMF cycle is moderate, such as in a gas turbine blade root, isothermal fatigue at the maximum temperature of the TMF cycle may be used as an approximation. Since isothermal fatigue testing is considerably less complex and time consuming than TMF testing, the amount of published data is larger for isothermal fatigue testing than for TMF testing. When it comes to TMF crack growth testing of single crystal superalloys, no previous publications were found. Some research has however been done regarding the crack growth behaviour of polycrystalline nickel base alloys under TMF conditions ${ }^{58,59,60,61,62,63,64}$. There are numerous publications regarding isothermal fatigue crack growth in single crystal nickel base super alloys. These are presented and discussed below.

Duquette, Gell and Piteo ${ }^{65}$ conducted an electron fractographic study of crystallographic fracture surfaces in smooth cylindrical single crystal MAR-M200 specimens tested at room temperature. The amount of slip bands and slip band cracks observed on the fracture surfaces differed between the upper and lower half of the specimen. This difference was explained by differences in the calculated glide forces on the possible slip systems near the crack tip.

Saxena and Antolovich ${ }^{66}$ investigated the fatigue crack propagation in single crystal CMSX- 2 at $25^{\circ} \mathrm{C}$ in air and at $700^{\circ} \mathrm{C}$ in air and in vacuum. CT specimens with two different crystal orientations were tested. At $25^{\circ} \mathrm{C}$ the crack growth was purely crystallographic and occurred exclusively along $\{111\}$ planes. At $700^{\circ} \mathrm{C}$ both mode I crack growth and octahedral crack growth was observed. In the case of Mode I crack growth at $700^{\circ} \mathrm{C}$, the crack was observed to avoid the gamma prime particles. It was proposed that the Mode I crack growth was crystallographic on the micro scale. The proposed crack advance mechanism for Mode I crack growth was that the crack was growing on $\{100\}$ planes at the $\gamma / \gamma^{\prime}$ interfaces and on $\{111\}$ planes through the $\gamma$ matrix.

The fatigue crack growth of PWA1480 at room temperature was studied by Telesman and $G \operatorname{sos}^{67}$, who observed a transition from octahedral $\{111\}$-cracking to $\{001\}$ cracking with decreasing $\Delta K$. Their proposed explanation for this observation was the inability of dislocations to cut through $\gamma^{\prime}$ particles at the low resolved shear stress 
associated with low $\Delta K$. They evaluated the results in terms of a resolved shear stress intensity parameter and used this to quantify the crack driving force and predict the crack path. Telesman and Ghosn ${ }^{68}$ also investigated the fatigue crack growth behaviour of PWA1484 at elevated temperatures.

Sengupta and Putanda ${ }^{69}$ studied the near-threshold fatigue crack growth behaviour of CMSX-4 CT specimens at $20^{\circ} \mathrm{C}, 650^{\circ} \mathrm{C}$ and $800^{\circ} \mathrm{C}$. They observed crystallographic zig-zag crack growth along $\{111\}$ planes at $20^{\circ} \mathrm{C}$ but not at the higher temperatures, where the fracture surfaces were smooth and flat. In the threshold region the cracks were observed to follow $\{100\}$-planes.

The crack growth behaviour of single crystal RENÉ N4 was studied by Lerch and Antolovich ${ }^{70}$ at temperatures of $21^{\circ} \mathrm{C}, 704^{\circ} \mathrm{C}, 927^{\circ} \mathrm{C}, 1038^{\circ} \mathrm{C}$ and $1093^{\circ} \mathrm{C}$, using CT specimens with two different crystal orientations. At $21^{\circ} \mathrm{C}$ the crack growth was initially crystallographic along $\{111\}$ planes but switched to non-crystallographic for $\Delta K$ above $35 \mathrm{MPa}^{*} \sqrt{\mathrm{m}}$. At the higher temperatures, crack growth was noncrystallographic.

Ma et al. ${ }^{71}$ investigated the influence of temperature on the low cycle fatigue crack growth behaviour of smooth cylindrical specimens of a single crystal nickel base superalloy. Crystallographic cracking on one or several $\{111\}$ planes was favoured at lower temperature, whereas crack growth was confined to the $\gamma$-matrix and the $\gamma / \gamma^{\prime}$ interfaces at higher temperature. In another publication by Ma et al. ${ }^{72}$, the LCF crack growth at $550^{\circ} \mathrm{C}$ in single edge notch specimens of a single crystal nickel base superalloy is studied by in-situ SEM. Specimens with three different crystal orientations were studied. At the surface studied by in-situ SEM, carbides present in the microstructure were found to have an influence on the local crack path and the local crack growth rate.

Kagawa and Mukai ${ }^{73}$ studied the influence of orientation and temperature on the LCF crack growth behaviour of CMSX-4 CT specimens with three different crystal orientations, tested at room temperature, $500^{\circ} \mathrm{C}, 700^{\circ} \mathrm{C}$ and $900^{\circ} \mathrm{C}$. They observed crystallographic cracking in all tests at room temperature, whereas tests at elevated temperature showed non-crystallographic cracking in the beginning of the tests with a transition to partly crystallographic cracking in some of the elevated temperature tests. The influence of crystal orientation on the fatigue crack growth behaviour of single crystal nickel base superalloys was also studied by Okazaki et.al ${ }^{74}$ and Zhang et al. ${ }^{75}$.

The isothermal fatigue crack growth behaviour of single crystal nickel base alloys has also been studied by other authors ${ }^{76,77,78,79,80,81}$. 
Similar fracture behaviour as in single crystal alloys has also been reported for columnar grained alloys. Gell and Leverant ${ }^{82}$ observed crystallographic crack growth on $\{111\}$ planes in smooth cylindrical specimens of a directionally solidified, nickel base superalloy tested in pulsating tension at room temperature. They observed fracture steps and striation-like features which they interpreted as indications that both normal stresses and shear stresses are involved in the crystallographic crack growth process, whereas the shear stresses alone were believed to control the selection of the crystallographic fracture plane. 


\section{Experimental work}

The experimental work consisted of fatigue crack growth testing and microscopy, aimed at characterizing the crack growth behaviour of a single crystal nickel base alloy under conditions representative of gas turbine blades. In a gas turbine blade, the conditions vary strongly between different potential crack initiation sites, both in terms of mechanical loading and temperature cycle. During TMF testing, the temperature can be cycled independently of the mechanical loading and thus it is possible to achieve very close resemblance to the real TMF loading induced by the start/stop cycle of the gas turbine. In the present work, data has been generated for a number of idealized TMF cycles as further described in section 5.2. Isothermal fatigue crack growth testing has also been done and the difference in material response between isothermal and TMF conditions has been evaluated. Two different types of specimens have been used for isothermal testing: disk shaped compact tension (DCT) specimens and single edge notch (SEN) specimens. For the TMF crack growth testing, only SEN specimens were used due to limitations of the test setup. The purpose of using different specimen geometries was to investigate if the crack growth rate was sensitive to the specimen geometry. This is an important aspect to consider when assessing the transferability of the crack growth data to a component such as a gas turbine blade.

\subsection{Isothermal crack growth testing of DCT specimens}

Isothermal fatigue crack growth testing was performed on DCT specimens, according to ASTM E $647^{83}$. The specimens were extracted, in three different crystallographic orientations, from a round bar with a diameter of $25 \mathrm{~mm}$, see Figure 5 . Tests were run at $20^{\circ} \mathrm{C}, 500^{\circ} \mathrm{C}$ and $750^{\circ} \mathrm{C}$ with stress ratio $\mathrm{R}=0.1$. The specimens had an Electro Discharge Machined (EDM) starter notch and were fatigue pre-cracked at room temperature with a frequency of $10 \mathrm{~Hz}$. During the pre-cracking and room temperature testing, the crack opening displacement was measured using a clip gauge extensometer and the crack length was determined by the compliance method described in ASTM E $647^{83}$. The fatigue crack growth tests at elevated temperature were run in a $100 \mathrm{kN}$ Zwick servo-electric tensile testing machine (Kappa 50DS), with a three zone furnace. At elevated temperature, the crack length was monitored using 
pulsed direct current potential drop measurement (DCPD). Further details are found in Paper 1.

a
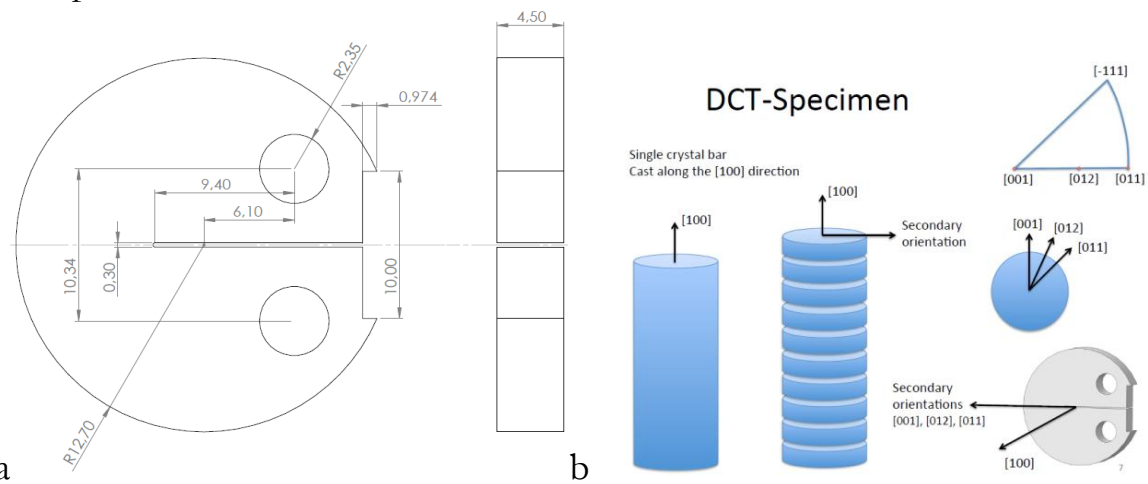

Figure 5 - a: Drawing of DCT specimen in units of $\mathrm{mm}$. b: Description of test specimen extraction.

\subsection{TMF and isothermal crack growth testing of SEN specimens}

In the present work, TMF crack growth testing is performed on $100 \mathrm{kN}$ servohydraulic testing machines using a test setup similar to the one previously used by Moverare ${ }^{30,34}$. Two different SEN specimens were used for the testing, see Figure 5. The nominal crystal orientation was [001] in the axial direction and [010] in the crack depth direction, except for two specimens where the secondary crystal orientation was rotated by $22,5^{\circ}$ from the [010] direction. The gauge length of the extensometer was $12 \mathrm{~mm}$. The specimens were heated by an induction coil and cooled by compressed air from two cooling nozzles, see Figure 6. The temperature was controlled using one thermocouple spot welded in the axial center of the gauge length on the side opposite the notch. A constant heating and cooling rate of $2^{\circ} \mathrm{C} / \mathrm{s}$ was used in all tests. In all TMF tests, the minimum temperature was $100^{\circ} \mathrm{C}$, whereas the maximum temperature was either $750^{\circ} \mathrm{C}$ or $850^{\circ} \mathrm{C}$. The hold time at maximum temperature was varied between $10 \mathrm{~s}, 1 \mathrm{~h}$ or $6 \mathrm{~h}$. All TMF tests were run in force control with the force cycle either in phase (IP-TMF) or $180^{\circ}$ out of phase (OP-TMF) relative to the thermal cycle. The majority of the tests were run with a stress ratio of $\mathrm{R}=-1$. This was chosen to be representative of the service conditions experienced by a gas turbine blade, with deformation controlled loading and substantial mean stress relaxation occurring before potential crack initiation. A few tests were run at higher R-ratios, mainly to improve the understanding of the crack closure behaviour. The crack length in each cycle was measured using the compliance method, adapted for TMF conditions. The crack growth as also monitored by a camera system but all crack length measurements were based on the compliance method. The crack opening force was evaluated using a 
newly developed compliance based method. The method is adapted to TMF conditions and thus takes into account the variation in elastic modulus throughout the TMF cycle. The gradual opening of the crack upon loading is characterized by calculating the stiffness decrease during loading relative to the stiffness during loading of the un-cracked specimen and comparing this with the relative stiffness decrease for the fully open crack during unloading. Based on this comparison, a parameter is defined to quantify the degree of crack opening and this parameter is used to setup a crack opening criterion. Further details regarding the testing and evaluation procedures are found in Paper 2. Based on the experimentally determined crack opening force, the effective stress intensity factor range $\Delta \mathrm{K}_{\text {eff }}$ can be obtained according Eq. (4). 


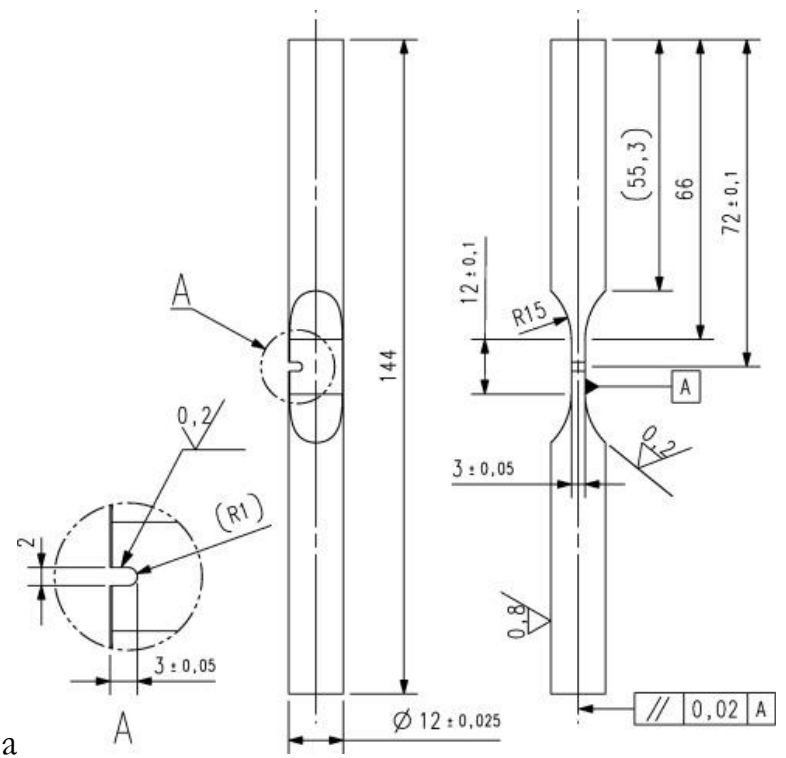

a

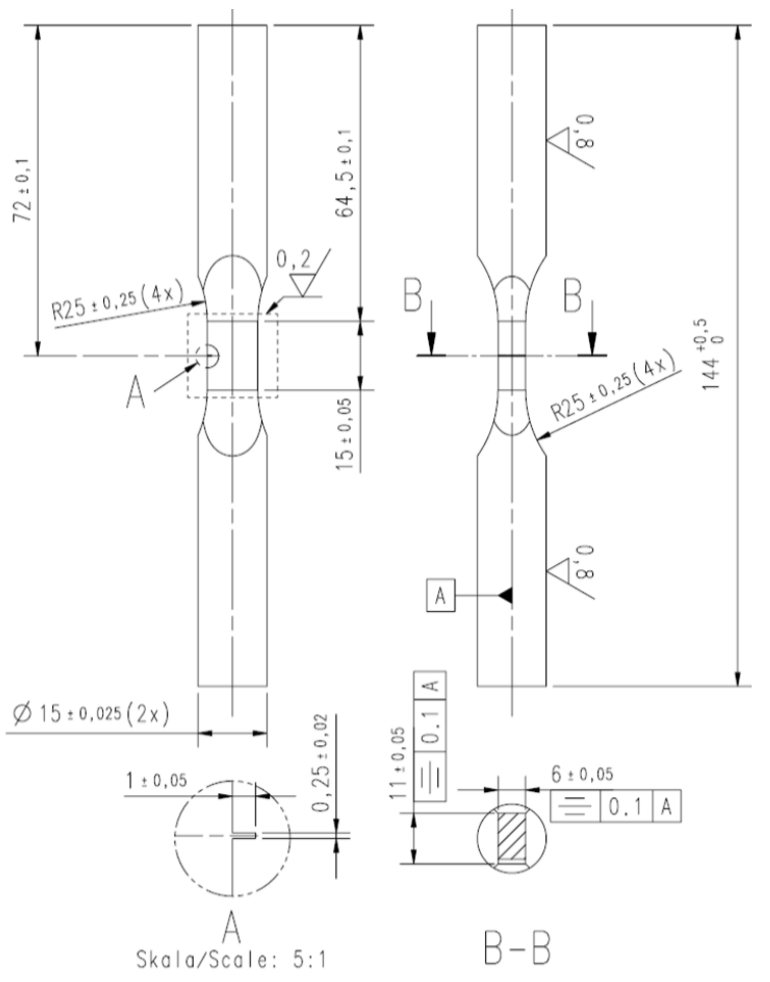

Figure 6 -Specimen drawings. a: Specimen SEN-1, b: Specimen SEN-2.

24 

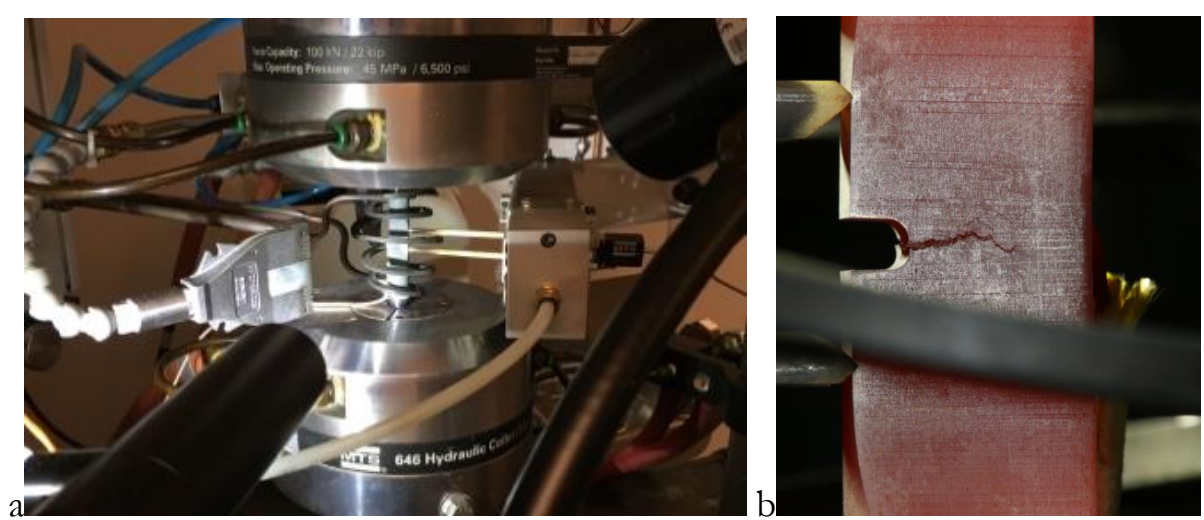

Figure 7 - a: Test set-up for TMF crack growth testing. b: Close-up of cracked specimen, showing the location of the extensometer rods.

\subsection{Microscopy}

Some of the tests were interrupted before final failure in order to allow microstructural investigation of the crack tip. Cross-sections were prepared at midthickness of the specimen by grinding and polishing down to $1 / 4 \mu \mathrm{m}$ grain size, followed by chemical polishing. No etching was performed on the specimens. The specimens were examined in a Hitachi SU70 FEG-SEM scanning electron microscope (SEM). Fracture surface examinations were also done, using stereo microscope and SEM. For the fracture surfaces, a JEOL JSM-6610LV tungsten filament SEM was used. 


\section{Summary of findings}

From a gas turbine perspective, it seems reasonable to assume that the TMF loading of a turbine blade root may be approximated by isothermal crack growth testing at the maximum operating temperature. This assumption is motivated by the microstructural stability at the operating temperature of the blade root and the fact that the mechanical loading is in phase with the temperature cycle. The platform and airfoil of a gas turbine blade are however exposed to much higher temperatures, which may result in microstructural degradation and the material response during TMF may be significantly different than during isothermal fatigue. TMF crack growth testing is thus motivated to generate relevant data for the platform and airfoil of a gas turbine blade. The typical distribution of metal temperature in a stage 1 gas turbine blade is schematically illustrated by Figure 1. Within this licentiate of engineering work, the crack growth behaviour of a single crystal nickel base superalloy has been studied, both under isothermal and TMF conditions. The testing and associated microstructural investigations directly address Aim 1 of the present work: "To improve the understanding of the fatigue crack growth behaviour of single crystal nickel base superalloys, under conditions representative of gas turbine blades."

The crack growth behaviour of single crystal superalloys under isothermal conditions has been previously studied ${ }^{65-80}$, although uncertainties still remain regarding the phenomenon of crystallographic crack growth. The localization of inelastic deformation to $\{111\}$ planes and crystallographic crack growth along these planes provides a major challenge in terms of test data evaluation and crack growth modelling for single crystal superalloys. The findings of the present work with regard to crystallographic crack growth are mostly in qualitative agreement with previous work on other single crystal superalloys. An unexpected result was however that the propensity for crystallographic crack growth in DCT specimens was higher at $500^{\circ} \mathrm{C}$ than at room temperature. The opposite would be expected based on the confinement of inelastic strains to the $\gamma$ matrix considering the temperature dependences of the critical resolved shear stress of the $\gamma$ and $\gamma^{\prime}$ phases respectively. This is further discussed in Paper 1. Kagawa and Mukai ${ }^{73}$ found that the propensity for crystallographic crack growth in CMSX-4 was indeed higher at room temperature than at $500^{\circ} \mathrm{C}$. The unexpected behaviour with regard to crystallographic crack growth at room temperature remains a topic for future investigation. During noncrystallographic crack growth, the cracks were observed to avoid the $\gamma^{\prime}$ particles, as reported in previous work ${ }^{66,67,81}$. Microstructural investigations indicated no specific 
preference for $\gamma / \gamma^{\prime}$ interfaces, or for certain crystallographic planes within the $\gamma$ phase. That is to say that the specific crack advance mechanism proposed by Saxena and Antolovich ${ }^{66}$ was not observed in the present tests. Crystallographic crack growth was clearly promoted by the plane stress conditions at the surfaces of the specimen. Since the crystallographic crack growth occurs on $\{111\}$ planes, there is a strong influence of crystal orientation on the propensity for crystallographic crack growth. For cracks growing in Mode I, no significant influence of crystal orientation was observed on the crack growth rate. In Paper 1, it was shown by finite element simulations that the stress intensity factor for the DCT specimen is significantly influenced by the elastic anisotropy of the material. Although there was a clear difference when comparing isotropic and anisotropic elastic properties, there was no significant difference when comparing the different anisotropic cases corresponding to the crystal orientations of the tested specimens. This may have been related to the fact that the low modulus $<001>$ direction was aligned with the thickness direction for all specimens. Previously published crack growth data for single crystal alloys has been based on $K$-solutions for isotropic material properties ${ }^{84,85,86}$. For the sake of comparability with previous results, the same approach was used when plotting the crack growth data in the present work. Further discussions regarding crystallographic crack growth and the influence of crystal orientation are found in Paper 1. As shown both in previous work and in Paper 1, crystallographic crack growth is mainly of concern for lower temperatures. This is not to say that crystallographic crack growth is only of concern for the parts of a turbine blade with low operating temperature. Hot spots on a turbine blade airfoil or platform give rise to thermal compressive stresses at maximum temperature and tensile stresses at minimum temperature, i.e. OP-TMF. The propagation of a crack under OP-TMF will thus occur at low temperature, even if the maximum operating temperature is very high. In a general OP-TMF case the complexities of crystallographic crack growth are thereby combined with the complexities of microstructural changes and creep at the maximum temperature. In the present work, the problem was separated by studying the crystallographic crack growth under isothermal conditions (Paper 1) and the OP-TMF behaviour of Mode I cracks (Paper 2). In order to study the OP-TMF behaviour of Mode I cracks, the test specimens were pre-cracked isothermally at a temperature high enough to avoid crystallographic crack growth. When the OP-TMF cycling was started, the crack continued to grow in Mode I. The same pre-cracking procedure was used to obtain isothermal Mode I crack growth data at $100^{\circ} \mathrm{C}$, which was the minimum temperature of the OP-TMF tests. The crack growth rates vs $\Delta K_{\text {eff }}$ during OP-TMF were significantly higher compared to isothermal testing at $100^{\circ} \mathrm{C}$, even though the crack advancement presumably occurs at the same temperature. Local dissolution of $\gamma^{\prime}$ and recrystallization at the crack tip is proposed as a likely explanation for the observed difference in crack growth rate. This explanation is based on microstructural observations, combined with the findings of other researchers regarding the facilitation of $\gamma^{\prime}$ dissolution by pipe diffusion of $\mathrm{Cr}$ and $\mathrm{Co}$ at dislocations ${ }^{20,87}$. The 
importance of recrystallization as a damage mechanism in OP-TMF tests on smooth single crystal specimens has been shown in previous reserach ${ }^{15,26,88}$.

An interesting observation from the IP-TMF and high temperature isothermal testing was that there was no significant difference in crack growth rate vs $\Delta K_{\text {eff }}$ between IPTMF tests and isothermal tests at the maximum temperature of the TMF cycle. The crack growth rate increased if a hold time of $1 \mathrm{~h}$ or more was applied at maximum load. Purely hold time dependent crack growth was only observed in one of the DCT specimens, tested isothermally with a stress ratio of $\mathrm{R}=0.1$ at $750^{\circ} \mathrm{C}$. At high maximum stress intensity factors $\left(K_{\max }>33 \mathrm{MPa}^{*} \mathrm{~m}^{\wedge} 0.5\right)$, there was a significant but moderate difference in crack growth rate between 30 s dwell and $1 \mathrm{~h}$ dwell. The difference increased with increasing $K_{\max }$. In this case, the hold time influence is believed to be due to crack growth occurring during the hold time. In the TMF testing of SEN specimens, the hold time influence was of a completely different nature. In this case, the influence of the hold time was to decrease the crack opening force, thereby accelerating the cycle dependent crack growth. A hold time of $1 \mathrm{~h}$ had the same influence on the crack opening force as a $6 \mathrm{~h}$ hold time and also the same influence on the crack growth rate. If any crack growth occurred during the hold time, it was insignificant compared to the cycle dependent crack growth. The difference between DCT and SEN testing is not only due to the specimen geometry itself, but also to the stress ratio selected for the testing. In the TMF testing and isothermal fatigue testing of SEN specimens the test setup allowed the usage of negative stress ratios, which was not the case in the DCT testing. The majority of the tests on SEN specimens were run at a stress ratio of $\mathrm{R}=-1$. This stress ratio was chosen to be representative of the service conditions experienced by a gas turbine blade, with deformation controlled loading and substantial mean stress relaxation occurring before potential crack initiation. The lower $K_{\max }$ associated with $\mathrm{R}=-1$ explains why the SEN specimens did not display any pure hold time dependent crack growth, but only an indirect influence of hold time through the reduction of crack opening stress.

Aim 2 of the present work was to: "Improve the testing and evaluation methodology for TMF crack growth". A significant improvement in evaluation methodology has been achieved through the development of a compliance based method to determine the crack opening force, which enables the calculation of the effective stress intensity factor range $\Delta K_{e f f}$ The ability to evaluate $\Delta K_{e f f}$ proved to be of vital importance for the test data analysis. As seen in the above discussion regarding the crack growth behaviour, the analysis of hold time influence relies heavily on the knowledge of the crack opening force. Improvements have also been done to the testing methodology. One example is the development of a suitable pre-cracking procedure to avoid crystallographic crack growth in OP-TMF tests, for cases where Mode I crack growth data is wanted. 


\section{Conclusions}

- Fatigue crack growth testing has been performed, both using conventional isothermal testing methods and also using thermomechanical fatigue crack growth testing, including tests with hold times at maximum load of up to $6 \mathrm{~h}$. A compliance based method for the evaluation of crack opening force under thermomechanical fatigue conditions was developed, in order to enable a detailed analysis of the test data. The crack opening force evaluation proved to be of key importance in the understanding of the crack driving force under different testing conditions, especially with regard to the hold time dependence of the crack opening force.

- The phenomenon of crystallographic crack growth along $\{111\}$ planes has been studied and its dependence on crystal orientation and testing temperature has been investigated. The findings of the present work with regard to crystallographic crack growth are mostly in qualitative agreement with previous work on other single crystal superalloys. However, an unexpected result was that the propensity for crystallographic crack growth in DCT specimens was higher at $500^{\circ} \mathrm{C}$ than at room temperature.

- Microstructural investigations have been undertaken to investigate the deformation mechanisms governing the crack growth behaviour. For OP-TMF loading, local dissolution of $\gamma^{\prime}$ and recrystallization at the crack tip appears to play a significant role in the crack growth behaviour. This confirms the importance of using TMF crack growth testing, rather than isothermal fatigue testing, in order to capture the relevant material behaviour from a gas turbine perspective. 


\section{Outlook}

Further work is planned regarding the influence of hold time on the crack growth rate, in order to enable modelling of the overall crack growth rate for a wide range of hold times and stress ratios. This will require additional testing, characterization and modelling work and perhaps also refinement of the data evaluation method. In the present work, it was seen that the crack opening force is hold time dependent and this will be further investigated and quantified in future work. Apart from the investigation of hold time influence, it is also of interest to study the influence of pretest aging on the crack growth behaviour.

The phenomenon of crystallographic crack growth remains a source of significant uncertainty in crack growth simulations on single crystal nickel base superalloys. Further testing, characterization and modelling work is required to derive a criterion which can be used to predict the transition from Mode I to crystallographic crack growth. 


\section{Bibliography}

${ }^{1}$ Stocker, T.F., D. Qin, G.-K. Plattner, L.V. Alexander, S.K. Allen, N.L. Bindoff, F.M. Bréon, J.A. Church, U. Cubasch, S. Emori, P. Forster, P. Friedlingstein, N. Gillett, J.M. Gregory, D.L. Hartmann, E. Jansen, B. Kirtman, R. Knutti, K. Krishna Kumar, P. Lemke, J. Marotzke, V. Masson-Delmotte, G.A. Meehl, I.I. Mokhov, S. Piao, V. Ramaswamy, D. Randall, M. Rhein, M. Rojas, C. Sabine, D. Shindell, L.D. Talley, D.G. Vaughan and S.-P. Xie, 2013: "Technical Summary. In: Climate Change 2013: The Physical Science Basis. Contribution of Working Group I to the Fifth Assessment Report of the Intergovernmental Panel on Climate Change" [Stocker, T.F., D. Qin, G.-K. Plattner, M. Tignor, S.K. Allen, J. Boschung, A. Nauels, Y. Xia, V. Bex and P.M. Midgley (eds.)]. Cambridge University Press, Cambridge, United Kingdom and New York, NY, USA.

${ }^{2}$ R.C. Reed, “The Superalloys: Fundamentals and applications", Cambridge, 2006, p. 103-107

${ }^{3}$ W. W. Milligan and S. D. Antolovich, "Deformation Modeling and Constitutive Modeling for Anisotropic Superalloys", NASA contractor report 4215, 1989

${ }^{4} \mathrm{~T}$. Tinga, "Stress intensity factors and crack propagation in a single crystal nickel-based superalloy", Engineering Fracture Mechanics 73, 2006.

${ }^{5}$ J. Telesman and L. J. Ghosn, "Fatigue crack growth behavior of PWA 1484 single crystal superalloy at elevated temperatures", Presented at the International Gas Turbine and Aeroengine Congress \& Exposition, Houston, Texas, June 5-8, 1995.

${ }^{6}$ M. Gell, G. R. Leverant, "The characteristics of stage I fatigue fracture in a highstrength nickel alloy", Acta Metallurgica, vol. 16, April 1968.

S. Ranjan, N. K. Arakere, A Fracture-Mechanics-Based Methodology for Fatigue Life Prediction of Single Crystal Nickel-Based Superalloys, Journal of Engineering for Gas Turbines and Power 130 (2008) 032501. 
${ }^{8}$ W. Qiu, X. Ma, S. Rui, H.-J. Shi, Crystallographic analysis on small fatigue crack propagation behaviour of a nickel-based single crystal superalloy, Fatigue and Fracture of Engineering Materials and Structures 40 (2017).

9 Busse, C., Palmert, F., Sjödin, B., Almroth, P., Gustafsson, D., Simonsson, K., Leidermark, D., "Prediction of crystallographic cracking planes in single-crystal nickel-base superalloys”, (2018) Engineering Fracture Mechanics, 196, pp. 206-223.

${ }^{10}$ Busse, C., Palmert, F., Wawrzynek, P., Sjödin, B., Gustafsson, D., Leidermark, D., "Crystallographic crack propagation rate in single-crystal nickelbase superalloys", (2018) MATEC Web of Conferences, 165, art. no. 13012.

${ }^{11}$ Arrell D, Hasselqvist M, Sommer J, Moverare J.On TMF Damage, Degradation Effects, and the Associated Tmin Influence on TMF Test Results in $\gamma / \gamma$ ' Alloys, in: Superalloys 2004.

${ }^{12}$ Moverare, Johan \& C. Reed, Roger. (2014). Thermomechanical fatigue in single crystal superalloys. MATEC Web of Conferences. 14. 06001. $10.1051 /$ matecconf/20141406001.

${ }^{13}$ Sato, Atsushi \& Moverare, Johan \& Hasselqvist, Magnus \& C. Reed, Roger. (2012). On the Mechanical Behavior of a New Single-Crystal Superalloy for Industrial Gas Turbine Applications. Metallurgical and Materials Transactions A. 43. 10.1007/s11661-011-0995-2.

${ }^{14}$ Hong, H \& Kang, J.G. \& Choi, Baig Gyu \& Kim, In \& S. Yoo, Y \& Y. Jo, C. (2011). A comparative study on thermomechanical and low cycle fatigue failures of a single crystal nickel-based superalloy. International Journal of Fatigue - INT J FATIGUE. 33. 1592-1599. 10.1016/j.ijfatigue.2011.07.009.

${ }^{15}$ Segersäll, M., Kontis, P., Pedrazzini, S., Bagot, P.A.J., Moody, M.P., Moverare, J.J., and Reed, R.C. (2015). Thermal-mechanical fatigue behaviour of a new single crystal superalloy: Effects of Si and Re alloying. Acta Materialia 95, 456-467.

${ }^{16}$ F. Sun, J. Zhang, H. Harada, Deformation twinning and twinning-related fracture in nickel-base single-crystal superalloys during thermomechanical fatigue cycling, Acta Mater., 67 (2014), pp. 45-57 
${ }^{17}$ Segersäll M, Moverare JJ, Leidermark D, Johansson S. In- and out-of-phase Thermomechanical Fatigueof a Ni-Based Single-Crystal Superalloy, in: EuroSuperalloys 2014

${ }^{18}$ G. M. Han, J. J. Yu, X. F. Sun, and Z. Q. Hu, "Thermo-mechanical fatigue behavior of a single-crystal nickel-based superalloy," Materials Science and Engineering A, vol. 528, pp. 6217-6224, 2011.

${ }^{19}$ Segersäll, Mikael \& Leidermark, Daniel \& Moverare, Johan. (2015). Influence of crystal orientation on the thermomechanical fatigue behaviour in a single-crystal superalloy. Materials Science and Engineering A. 623. 68-77. 10.1016/j.msea.2014.11.026.

20 P. Kontis et al., The Role of Oxidized Carbides on Thermal-Mechanical Performance of Polycrystalline Superalloys. Metallurgical and Materials Transactions A: Physical Metallurgy and Materials Science. 49, 4236-4245 (2018)

${ }^{21}$ Moverare, Johan \& Segersäll, Mikael \& Sato, Atsushi \& Johansson, Sten \& Roger, Reed. (2012). Thermomechanical Fatigue of Single-Crystal Superalloys: Influence of Composition and Microstructure. Proceedings of the International Symposium on Superalloys. 10.1002/9781118516430.ch40.

${ }^{22}$ Zhang, J.X. \& Harada, H \& Ro, Y \& Koizumi, Yuichiro \& Kobayashi, T. (2008). Thermomechanical fatigue mechanism in a modern single crystal nickel base superalloy TMS-82. Acta Materialia. 56. 2975-2987. 10.1016/j.actamat.2008.02.035.

${ }^{23}$ Sun, Fei \& Zhang, Jianxin \& Harada, Hiroshi. (2014). Deformation twinning and twinning-related fracture in nickel-base single-crystal superalloys during thermomechanical fatigue cycling. Acta Materialia. 67. 45-57. 10.1016/j.actamat.2013.12.011.

${ }^{24}$ Neuner, F.C. \& Tetzlaff, Ulrich \& Mughrabi, Hael. (2003). Enhancement of Thermomechanical Fatigue Resistance of a Monocrystalline Nickel-base Superalloy by Pre-rafting. ASTM Special Technical Publication. 112-126.

${ }^{25}$ Zhang, J.X. \& Harada, H \& Ro, Y \& Koizumi, Yuichiro. (2006). Superior thermomechanical fatigue property of a superalloy due to its heterogeneous microstructure. Scripta Materialia. 55. 731-734. 10.1016/j.scriptamat.2006.06.012. 
${ }^{26}$ Johansson, Sten \& Moverare, Johan \& Leidermark, Daniel \& Simonsson, Kjell \& Kanesund, Jan. (2010). Investigation of localized damage in single crystals subjected to thermalmechanical fatigue (TMF). Procedia Engineering. 2. 657-666. 10.1016/j.proeng.2010.03.071.

${ }^{27} \mathrm{Yu}$, Jinjiang \& Han, Guoming \& Chu, Zhaokuang \& Sun, Xiaofeng \& Jin, T \& Hu, Zhuangqi. (2014). High temperature thermo-mechanical and low cycle fatigue behaviors of DD32 single crystal superalloy. Materials Science and Engineering: A. 592. 164-172. 10.1016/j.msea.2013.10.055.

${ }^{28}$ Zhang, P., Zhu, Q., Chen, G., Wang, C., "Review on thermo-mechanical fatigue behavior of nickel-base superalloys" Materials Transactions, (2015) 56 (12), pp. 19301939.

${ }^{29}$ Rau, C.A. \& Gemma, A.E. \& Leverant, G.R.. (1973). Thermal-mechanical fatigue crack propagation in nickel and cobalt base superalloys under various straintemperature cycles. ASTM STP. 520. 166-178.

30 P. Kontis et al., in Superalloys 2016 (John Wiley \& Sons, Inc., 2016; http://doi.wiley.com/10.1002/9781119075646.ch82), pp. 763-772.

${ }^{31}$ Kraemer, Karl \& Mueller, Falk \& Oechsner, M. (2017). Application-oriented description of time-/temperature dependent crack growth in a conventionally cast nickel-based superalloy. International Journal of Fatigue. 96. 78-88. 10.1016/j.ijfatigue.2016.11.025.

32 Esmaeilzadeh, Mojtaba \& Qods, Fathallah \& Arabi, Hossein \& Mohammad Sadeghi, Bagher. (2016). An investigation on crack growth rate of Fatigue and induction heating thermo-mechanical fatigue (TMF) in Hastelloy $\mathrm{X}$ superalloy via LEFM, EPFM and integration models. International Journal of Fatigue. 97. 135-149. 10.1016/j.ijfatigue.2016.12.036.

${ }^{33}$ T. Radzicki, A \& S. Johnson, W \& Neu, Richard \& Annigeri, Balkrishna \& Ziegler, Brett. (2017). Impact of compressive hold on out-of-phase thermomechanical fatigue crack growth in IN 718: Impact of Compressive Hold on OP TMF Crack Growth in IN 718. Fatigue \& Fracture of Engineering Materials \& Structures. 40. $10.1111 /$ ffe. 12584 . 
${ }^{34}$ Moverare, Johan \& Kontis, Paraskevas \& Johansson, Sten \& C. Reed, Roger. (2014). Thermomechanical fatigue crack growth in a cast polycrystalline superalloy. MATEC Web of Conferences. 14. 10.1051/matecconf/20141419004.

${ }^{35}$ R.C. Reed, "The Superalloys: Fundamentals and applications", Cambridge, 2006, p. 33-107

${ }^{36}$ F.T. Furillo, J.M. Davidson, J.K. Tien and L.A. Jackman, "The effects of grain boundary carbides on the creep and back stress of a nickel-base superalloy", Materials Science and EngineeringVolume 39, Issue 2, August 1979, Pages 267-273

${ }^{37}$ R.C. Reed, “The Superalloys: Fundamentals and applications”, 2006, p. 40

${ }^{38}$ R.C. Reed, “The Superalloys: Fundamentals and applications”, 2006, p. 353

${ }^{39}$ R.C. Reed, “The Superalloys: Fundamentals and applications”, 2006, p. 154-155

${ }^{40}$ R.C. Reed, “The Superalloys: Fundamentals and applications”, 2006, p. 81

${ }^{41}$ Murakumo, T., Kobayashi, T., Koizumi, Y., Harada, H. "Creep behaviour of Nibase single-crystal superalloys with various $\gamma^{\prime}$ volume fraction", (2004), Acta Materialia, 52 (12), pp. 3737-3744. DOI: 10.1016/j.actamat.2004.04.

${ }^{42}$ Segersäll, Mikael, "On Thermomechanical Fatigue of Single-Crystal Superalloys", Linköping Studies in Science and Technology Dissertation No. 1626, 2014

${ }^{43}$ E.S. Fisher, "On the Elastic Moduli of Nickel Rich Ni-Al Alloy Single Crystals", Scripta Metallurgica, vol 20, 1986, pp. 279-284

${ }^{44}$ R.C. Reed, J.J. Moverare, A. Sato, F. Karlsson, M. Hasselqvist, “A new single crystal superalloy for power generation applications", Superalloys 2012: 12th International Symposium on Superalloys, TMS, 2012

45 Bullough, C.K. \& Toulios, Michael \& Oehl, M \& Lukáš, P. (1998). "The characterization of the single crystal superalloy CMSX-4 for industrial gas turbine blading applications", J.Lecomte-Beckers et al (eds.) Materials for Advanced Power 
Engineering 1998, Part II, 861-878 Forschungszentrum Jülich 1998, Printed in Jülich, Germany

${ }^{46}$ Anderson T.L., "Fracture mechanics: Fundamentals and Applications", 2017, p. 4445.

Irwin, G.R.. (1956). Onset of fast crack propagation in high strength steel and aluminum alloys. Sagamore Research Conference Proceedings. 2. 289-305.

${ }^{48}$ A. Griffith, A. (1921). The phenomena of rupture and flows in solids. Philos. Trans. Roy. Soc. Lond.. 221.

${ }^{49}$ W. Elber, "Fatigue crack closure under cyclic tension", (1970) Engineering Fracture Mechanics, 2 (1), pp. 37-44

${ }^{50}$ P. Paris, F. Erdogan, "A critical analysis of crack propagation laws", (1963) Journal of Fluids Engineering, Transactions of the ASME, 85 (4), pp. 528-533.

51 Christian Busse, "Aspects of Crack Growth in Single-Crystal Nickel-Base Superalloys", Linköping Studies in Science and Technology Licentiate of engineering thesis No. 1794, 2017

${ }^{52}$ G.R. Irwin, (1960). "Plastic zone near a crack and fracture toughness". In: Proceedings of the 7th Sagamore Research Conference on Mechanics \& Metals Behavior of Sheet Material. New York. 4. 463-478.

${ }^{53}$ D.S. Dugdale, (1960). "Yielding of Steel Sheets Containing Slits", Journal of the Mechanics and Physics of Solids 8. 100-104.

${ }^{54}$ G. Barenblatt, (1962). "Mathematical theory of equilibrium cracks", Advances in Applied Mechanics 7. 56-129.

${ }^{55}$ Rice, James. (1968). "A path independent integral and the approximate analysis of strain concentration by notches and cracks", Journal of Applied Mechanics 35, 1968, 379-386

${ }^{56}$ J.D Landes, J.A. Begley, (1976). "A Fracture Mechanics Approach to Creep Crack Growth”, ASTM Special technical publication. 590. 128-148. 
${ }^{57}$ K. Nikbin, G.A. Webster, C.E. Turner, (1976). "Relevance of nonlinear fracture mechanics to creep crack growth" ASTM STP. 601. 47-62.

${ }^{58}$ Rau, C.A. \& Gemma, A.E. \& Leverant, G.R.. (1973). Thermal-mechanical fatigue crack propagation in nickel and cobalt base superalloys under various straintemperature cycles. ASTM STP. 520. 166-178.

59 P. Kontis et al., in Superalloys 2016 John Wiley \& Sons, Inc., 2016; http://doi.wiley.com/10.1002/9781119075646.ch82), pp. 763-772.

${ }^{60}$ Kraemer, Karl \& Mueller, Falk \& Oechsner, M. (2017). Application-oriented description of time-/temperature dependent crack growth in a conventionally cast nickel-based superalloy. International Journal of Fatigue. 96. 78-88. 10.1016/j.ijfatigue.2016.11.025.

${ }^{61}$ Moverare, J.J., and Gustafsson, D. (2011). Hold-time effect on the thermomechanical fatigue crack growth behaviour of Inconel 718. Materials Science and Engineering A 528, 8660-8670.

${ }^{62}$ Esmaeilzadeh, Mojtaba \& Qods, Fathallah \& Arabi, Hossein \& Mohammad Sadeghi, Bagher. (2016). An investigation on crack growth rate of Fatigue and induction heating thermo-mechanical fatigue (TMF) in Hastelloy $\mathrm{X}$ superalloy via LEFM, EPFM and integration models. International Journal of Fatigue. 97. 135-149. 10.1016/j.ijfatigue.2016.12.036.

${ }^{63}$ T. Radzicki, A \& S. Johnson, W \& Neu, Richard \& Annigeri, Balkrishna \& Ziegler, Brett. (2017). Impact of compressive hold on out-of-phase thermomechanical fatigue crack growth in IN 718: Impact of Compressive Hold on OP TMF Crack Growth in IN 718. Fatigue \& Fracture of Engineering Materials \& Structures. 40. $10.1111 /$ ffe.12584.

${ }^{64}$ Moverare, Johan \& Kontis, Paraskevas \& Johansson, Sten \& C. Reed, Roger. (2014). Thermomechanical fatigue crack growth in a cast polycrystalline superalloy. MATEC Web of Conferences. 14. 10.1051/matecconf/20141419004.

${ }^{65}$ D. J. Duquette, M. Gell and J. W. Piteo, "A fractographic study of stage I fatigue cracking in a Nickel-Base Superalloy Single Crystal”, Metallurgical transactions, Vol. 1, November 1970. 
${ }^{66}$ B.F. Antolovich, A. Saxena and S.D. Antolovich, "Fatigue Crack Propagataion in Single-Crystal CMSX-2 at Elevated Temperature", Journal of materials engineering and performance, Vol. 2, pp 489-496, 1993

${ }^{67}$ Jack Telesman and Lois J. Ghosn, "The Unusual Near-Threshold FCG Behavior of a Single Crystal Superalloy and the Resolved Shear Stress as the Crack Driving Force", Engineering Fracture Mechanics Vol. 34, No. 516, pp. 1183-1196, 1989.

${ }^{68}$ Jack Telesman and Lois J. Ghosn, "Fatigue crack growth behavior of PWA 1484 single crystal superalloy at elevated temperatures", Presented at the International Gas Turbine and Aeroengine Congress \& Exposition, Houston, Texas, June 5-8, 1995.

${ }^{69}$ Abhijit Sengupta and Susil K. Putatunda, "Influence of dynamic strain aging on the near-threshold fatigue crack growth behavior of a new single crystal nickel-based superalloy", Scripta Metallurgica et Materialia, vol. 31, No 9, pp. 1163-1168, 1994.

${ }^{70}$ B.A. Lerch and Stephen D. Antolovich, "fatigue Crack Propagation Behavior of a Single Crytsalline Superalloy", Metallurgical transactions A, Vol. 21A, pp 2169-2177, 1990

71 Xianfeng Ma, Huiji Shi, Jialin Gu, Zhaoxi Wang, Harald Harders, Thomas Malow, “Temperature Effect on Low-Cycle Fatigue Behavior of Nickel-Based Single Crystalline Superalloy", Acta Mechanica Solida Sinica, Vol. 21, No. 4, August, 2008

${ }^{72}$ Xianfeng Ma, Huiji Shi, Jialin Gu, Guofeng Chen, Oliver Luesebrink and Harald Harders, "In-situ observations of the effects of orientation and carbide on low cycle fatigue crack propagation in a single crystal superalloy", Procedia Engineering 2 (2010), pp 2287-2295, 2010

73 Hiroyuki Kagawa, Yasuhiro Mukai, "The Effect of Crystal Orientation and Temperature on Fatigue Crack Growth of Ni-based Single Crystal Superalloy", Superalloys 2012: 12th International Symposium on Superalloys, TMS, 2012

74 M. Okazaki, M. Sakaguchi, S. Yamagishi, "Subcritical Crack Growth on Crystallographic Planes in a Ni-base Superalloy: Relevance to Orientations", Procedia Engineering 55 ( 2013 ) 677 - 684, 2013. 
${ }^{75}$ Yangyang Zhang, Wenhui Qiu, Hui-Ji Shi, Changpeng Li, Kai Kadau, Oliver Luesebrink, "Effects of secondary orientations on long fatigue crack growth in a single crystal superalloy", Engineering Fracture Mechanics 136 (2015) 172-184, 2015.

${ }^{76}$ A. Defresne and L. Remy, "Fatigue Behaviour of CMSX 2 Superalioy [001] Single Crystals at High Temperature II: Fatigue Crack Growth", Materials Science and Engineering, A129 (1990) 55-64.

77 D. A. Wilson, D. P. Deluca, B. A. Cowles and M. A. Stucke, "Fatigue Crack Growth Resistance of Advanced Blade Materials", J. Eng. Gas Turbines Power 109(2), 176-181, Apr 01, 1987, doi:10.1115/1.3240021

${ }^{78}$ M. D. Miller, P. A. S. Reed, M. R. Joyce, M. B. Henderson, J. W. Brooks, I. Wilcock \& X. Wu (2007), "Effect of environment on notch fatigue behaviour in CMSX-4“, Materials Science and Technology, 23:12, 1439-1445, DOI: $10.1179 / 174328407 X 213198$

${ }^{79}$ Kwai S. Chan, James H. Feiger, Yi-Der Lee and Stephen J. Hudak, Jr, „Mixed-ode fatigue crack growth thresholds of a Ni-based single crystal alloy", David L Davidson Fatigue symposium, edited by K.S. Chan, PK Liaw, R.S. Bellows, L.C. Zogas and W.O Soboyejo, TMS, 2002.

${ }^{80}$ M.R. Joyce and P.A.S. Reed, "Fatigue crack growth behaviour under mixed mode loading in Udimet 720 SX", Superalloys 2004, Edited by K.A. Green, T.M. Pollock, H. Harada,T.E. Howson, R.C. Reed, J.J. Schirra, and S, Walston, , TMS (The Minerals, Metals \& Materials Society), 2004.

81 Suzuki, S., Sakaguchi, M., Inoue, H., "Temperature dependent fatigue crack propagation in a single crystal Ni-base superalloy affected by primary and secondary orientations", (2018) Materials Science and Engineering A, 724, pp. 559-565.

${ }^{82}$ M. Gell, G. R. Leverant, "The characteristics of stage I fatigue fracture in a highstrength nickel alloy", Acta Metallurgica, vol. 16, April 1968.

83 Standard Test Method for Measurement of Fatigue Crack Growth Rates, ASTM $\mathrm{E} 647,2014$ 
${ }^{84}$ K. S. Chan and T. A. Cruse, "Stress intensity factors for anisotropic compacttension specimens with inclined cracks", Engineering fracture mechanics, Vol. 23, No. 5, pp. 863-874, 1986.

${ }^{85}$ J.C. Newman, Jr, "Stress-intensity factors and crack-opening displacements for round compact specimens", International journal of fracture, Vol. 17, No. 6, December 1981.

${ }^{86}$ A. Sengupta and S. K. Putatunda, "Influence of dynamic strain aging on the nearthreshold fatigue crack growth behavior of a new single crystal nickel-based superalloy", Scripta Metallurgica et Materialia, vol. 31, No 9, pp. 1163-1168, 1994.

${ }^{87}$ Kontis, Paraskevas \& Li, Zhuangming \& Collins, David \& Cormier, Jonathan \& Raabe, Dierk \& Gault, Baptiste. (2018). The effect of chromium and cobalt segregation at dislocations on nickel-based superalloys. Scripta Materialia. 145. 76. 10.1016/j.scriptamat.2017.10.005.

${ }^{88}$ Moverare, Johan \& Johansson, Sten. (2010). Damage mechanisms of a high-Cr single crystal superalloy during thermomechanical fatigue. Materials Science and Engineering A. 527. 553-558. 10.1016/j.msea.2009.08.023. 


\section{Part 2 \\ Appended papers}




\section{Papers}

The papers associated with this thesis have been removed for copyright reasons. For more details about these see:

http://urn.kb.se/resolve?urn=urn:nbn:se:liu:diva-153619 



\section{FACULTY OF SCIENCE AND ENGINEERING}

Linköping Studies in Science and Technology, Licentiate thesis No. 1829, 2019 Department of Management and Engineering

Linköping University

SE-581 83 Linköping, Sweden

www.liu.se 